\title{
Effect Analysis of Removing Lead and Arsenic from contaminated soil by Selected Eluents
}

\author{
Ying Liu ${ }^{1,2}$, Xiaomao Yang ${ }^{1}$, Hui Zeng ${ }^{3}$, Zhenye Zhao ${ }^{1}$, Tingting $\mathrm{Xu}^{2}$ and Menghan Wang ${ }^{2}$ \\ ${ }^{1}$ PKU-HKUST Shenzhen-Hongkong Institution, 518057, Shenzhen, Guangdong \\ ${ }^{2}$ Chongqing Environment Engineering Academu Co., Ltd, 400021, Chongqing \\ ${ }^{3}$ Peking University Shenzhen Graduate School, 518057, Shenzhen, Guangdong
}

\begin{abstract}
In order to reduceof the amount of lead and arsenic in contaminated soil, CA(citric acid), PA(polyepoxysuccinic acid), MA(malic acid) and EDTA were used to remove as chemical extractor. The experiments showed that the extraction ability of lead was EDTA $>$ CA $>$ MA $>$ PA, and of arsenic was $\mathrm{MA}>\mathrm{CA}>\mathrm{PA}=\mathrm{EDTA}$. The eluents concentration, reaction period and liquid/solid ratio were the key factor of extraction effect. It was evident that the optimal condition was $0.1 \mathrm{~mol} / \mathrm{L}$ eluent and $2 \mathrm{~h}$ of extraction period.
\end{abstract}

\section{Introduction}

China conducted a national soil survey in 2014 and began a sophisticated quality survey of both agricultural and construction land in 2016. The results show that China faces a serious soil pollution problem, especially polluted by heavy metal. In accordance with international practice, China has set its own screening value for soil pollution risk[1]. Based on these values, the rapid industrial development over the past few decades has resulted in a large amount of pollutants accumulated in the soil. Due to China's rapid development of the huge demand for residential land, if this type of land converted to residential land for community development, the health of residents is in a great risk[2, 3]. In such case, Chinese society urgently needs to carry out targeted soil pollution remediation.

The current methods of soil remediation include physical means represented by the soil transferring, chemical means represented by the washing method, and biological means represented by plant restoration[4]. In order to meet the demand of construction land and the safety of residents, washing methods are highly respected[5, 6]. Its main advantages include soil pollutant reduction, rapid and effective, without transferring large amount of soil.

This study presents the soil pollution of lead and arsenic in a lead battery production site in southern China is remediated using organic and inorganic efficiency washing agents. The optimal washing parameters are determined. The scheme, in conjunction with the comprehensive wastewater disposal technology, can solve the problem of soil pollution in low cost, efficient and quantity reduction way.

\section{Material and method}

\subsection{Soil sample}

The samples were obtained from $0 \mathrm{~m}-4 \mathrm{~m}$ below the ground surface in a lead battery production site in southern China. The red earth soil was air dried, sieved $(2 \mathrm{~mm})$ and mixed. Each run of experiments were conducted to $500 \mathrm{~g}$ samples, screened through $0.149 \mathrm{~mm}$ nylon sieve. Physical and chemical properties of soil were shown in table 1 . The content of lead and arsenic exceeded the screening value of China (GB36600-2018).

Table 1. Physical and chemical index of the tested soils before remediation $\left(\mathrm{mg} \cdot \mathrm{kg}^{-1}\right)$.

\begin{tabular}{|c|c|}
\hline Soil properties & Value \\
\hline $\mathrm{pH}$ & 7.12 \\
\hline Organic matter content $(\mathrm{mg} / \mathrm{kg})$ & 19.1 \\
\hline moisture content $(\%)$ & 18.3 \\
\hline soil bulk density $\left(\mathrm{g} / \mathrm{cm}^{3}\right)$ & 1.08 \\
\hline $\mathrm{Cd}(\mathrm{mg} / \mathrm{kg})$ & 0.47 \\
\hline $\mathrm{Pb}(\mathrm{mg} / \mathrm{kg})$ & 1747.12 \\
\hline $\mathrm{As}(\mathrm{mg} / \mathrm{kg})$ & 21.7 \\
\hline $\mathrm{Hg}(\mathrm{mg} / \mathrm{kg})$ & 0.041 \\
\hline $\mathrm{Ni}(\mathrm{mg} / \mathrm{kg})$ & 20 \\
\hline $\mathrm{Cu}(\mathrm{mg} / \mathrm{kg})$ & 40 \\
\hline
\end{tabular}

\subsection{Soil Characterization}

Soil $\mathrm{pH}$ was measured in a $1: 2.5(\mathrm{w} / \mathrm{v})$ ratio of soil to distilled water using a $\mathrm{pH}-$ meter (HQ-40d). Soil organic 
matter was measured using peripheral heating method of potassium dichromate. The soil moisture content was determined by oven drying method. Soil bulk density was determined by soil wreath knife. The total amount of $\mathrm{Cd}, \mathrm{Pb}$ and $\mathrm{Cr}$ in soil was digested by $\mathrm{HNO} 3-\mathrm{HCl}-\mathrm{HF}$ microwave, and the digestion solution was determined by atomic absorption spectrophotometer (AAS). The total amount of $\mathrm{Hg}$ and $\mathrm{As}$ in the soil were digested by $\mathrm{HNO} 3-\mathrm{HCl}$ microwave, and the solution was determined by atomic fluorescence spectrophotometer (AFS).

\subsection{Eluent Production}

Citric acid(CA), polyepoxysuccinic acid(PA), malic $\operatorname{acid}(\mathrm{MA})$ and EDTA were selected as eluents. All the solutions were prepared at $0.01 \mathrm{~mol} / \mathrm{L}, 0.02 \mathrm{~mol} / \mathrm{L}$, $0.05 \mathrm{~mol} / \mathrm{L}, \quad 0.1 \mathrm{~mol} / \mathrm{L}, \quad 0.2 \mathrm{~mol} / \mathrm{L}, \quad$ and $\quad 0.5 \mathrm{~mol} / \mathrm{L}$ respectively. All the chemicals were procured as analytical grade from China Chemical Factory, Shanghai, China (purity $\geq 99 \%$ ).

\subsection{Extraction Procedure}

Four sets of extraction experiments were conducted to assess the effects of eluents; reaction time, liquid/solid ratio and eluent concentrations. The extraction tests were conducted in $50 \mathrm{~mL}$ polyethylene tubes. The tubes containing a measured volume of soils and different concentrations $\quad(0.01 \mathrm{~mol} / \mathrm{L}, \quad 0.02 \mathrm{~mol} / \mathrm{L}, \quad 0.05 \mathrm{~mol} / \mathrm{L}$, $0.1 \mathrm{~mol} / \mathrm{L}, \quad 0.2 \mathrm{~mol} / \mathrm{L}$, and $0.5 \mathrm{~mol} / \mathrm{L})$ of eluents in different solid/liquid ratio (1:3, 1:5, 1:10, 1:20). Each run were agitated using an end-over-end shaker at a speed of $180 \mathrm{rpm}$ at room temperature $\left(26^{\circ} \mathrm{C}-30^{\circ} \mathrm{C}\right)$ for a given time $(0.5 \mathrm{~h}, 1 \mathrm{~h}, 2 \mathrm{~h}, 4 \mathrm{~h}, 6 \mathrm{~h}, 8 \mathrm{~h})$. The suspensions were centrifuged at the rotating speed of $4000 \mathrm{rpm}$ for $15 \mathrm{~min}$ and the supernatants were then filtered for heavy metal analysis. The concentrations of lead was measured by AAS, and the concentrations of arsenic was measured by AFS.

The percent of each metal removed were calculated using the following equation:

$$
\text { Percent of metal removed(\%)= } \frac{C_{1} V_{1}}{C_{S} M_{S}} \times 100 \text { [7] }
$$

where $\mathrm{C} 1$ and $\mathrm{CS}$ are the concentrations of metal in supernatant (in $\mathrm{mg} / \mathrm{L}$ ) and soil $(\mathrm{mg} / \mathrm{kg}$ ), respectively; V1 is the volume of supernatant (in L) and MS is the dry mass of the soil $(\mathrm{kg})$.

\section{Results and Discussion}

\subsection{Comparison of different Eluents}

The same concentration $(0.1 \mathrm{~mol} / \mathrm{L})$ of $\mathrm{CA}, \mathrm{PA}, \mathrm{MA}$, EDTA were used as eluents and no $\mathrm{pH}$ djustment was made in the experiments of soil extraction. The extraction efficiency has been shown in Figure 1. The extraction efficiency of lead was higher than arsenic. The efficiency order of extraction of lead was EDTA $>$ CA $>$ MA $>$ PA, while $\mathrm{MA}>\mathrm{CA}>\mathrm{PA}=\mathrm{EDTA}$ for arsenic. Based on the experimental results, the best eluent for lead contaminated soil was EDTA, the best eluents for arsenic contaminated soil was CA and MA, and the best eluent for pollutants mixture was CA.

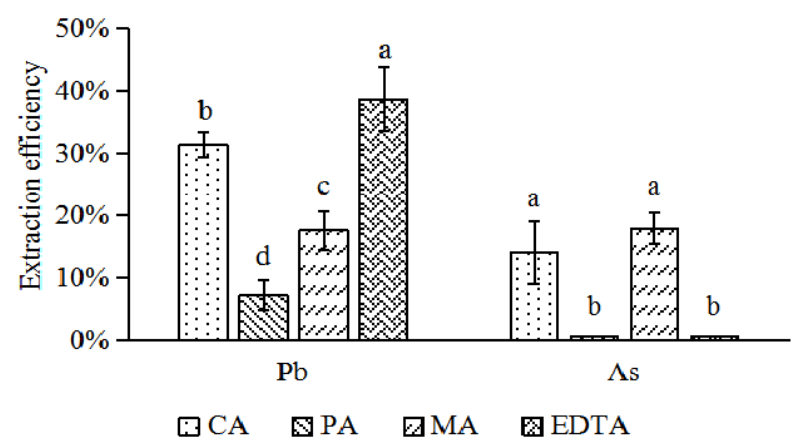

Figure 1. Extraction efficiency of different concentrations of eluents. (liquid $/$ solid $=10$, reaction time $=2 \mathrm{~h}$ )

\subsection{Influence of Eluents Concentration}

Different concentrations of CA, MA, EDTA were used and the extraction results are shown in Figure 2. The removal of lead and arsenic increased with increasing CA, MA, EDTA concentration from 0.001 to $0.5 \mathrm{~mol} / \mathrm{L}$ in a logarithmic pattern. The removal of lead by EDTA was $29.73 \%, 32.09 \%, 33.41 \%, 38.68 \%, 39.61 \%$ and $42.95 \%$ when the concentration was $0.01,0.02,0.05,0.1$, 0.2 and $0.5 \mathrm{~mol} / \mathrm{L}$, respectively. The removal of arsenic was obviously increased from $3.06 \%$ to $17.86 \%$, when the MA concentrate increased from 0.01 to $0.1 \mathrm{~mol} / \mathrm{L}$, and then reached a constant level at around $18 \%$. The extraction efficiency of CA for lead and arsenic was about $30 \%$ and $15 \%$ respectively when the concentration of CA was more than $0.1 \mathrm{~mol} / \mathrm{L}$. These results indicated that EDTA, CA and MA concentration had effect on the removal efficiency of lead and arsenic. But when the dose of eluent was enough for the requirement of soil, the influence was very slight. The critical level of EDTA, $\mathrm{CA}$ and MA in this study was $0.1 \mathrm{~mol} / \mathrm{L}$.

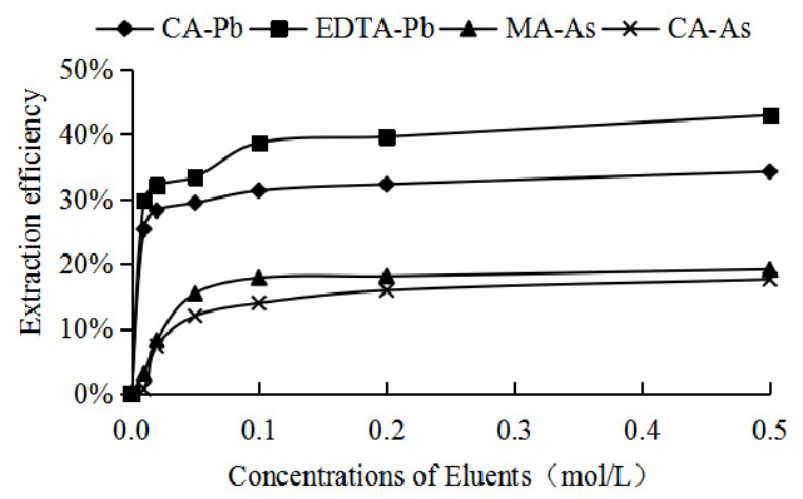

Figure 2. Extraction efficiency of different concentrations of eluents (liquid/solid $=10$, reaction time $=2 \mathrm{~h}$ )

\subsection{Influence of Leaching Time}

The extract efficiency increased with the reaction time linearly in the first 2 hours (Figure 3). Extending the 
reaction time from $2 \mathrm{~h}$ to $8 \mathrm{~h}$ had little effect on the efficiency. The possible reason is that extracted lead/arsenic is re-dissolved. The extraction efficiency of lead by EDTA increased from $28.9 \%$ to $38.68 \%$ from 0.5 $\mathrm{h}$ to $2 \mathrm{~h}$, and then reached a constant level at around $40 \%$ after $2 \mathrm{~h}$. While the arsenic extraction efficiency of MA increased from $10.30 \%$ to $17.86 \%$ during the first $2 \mathrm{~h}$ and reached the plateau. The extraction efficiency of CA for lead and arsenic remained around $38 \%$ and $16 \%$ after $2 \mathrm{~h}$. Therefore, a reaction time of $2 \mathrm{~h}$ was chosen for the following experiments.

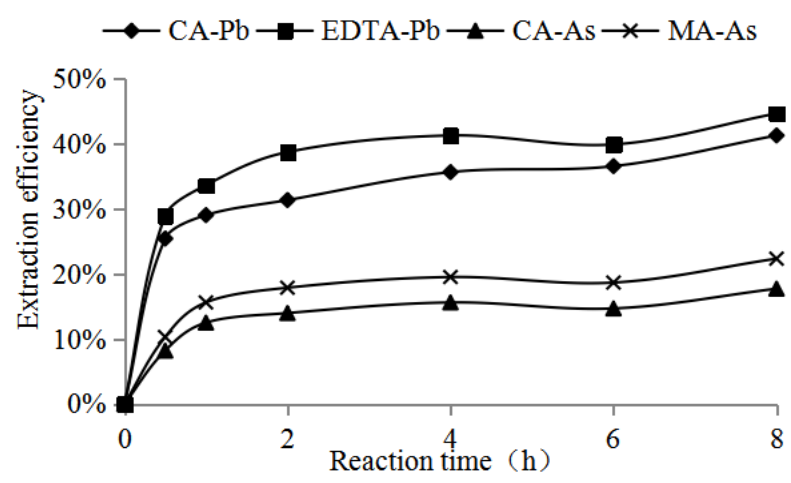

Figure 3. Extraction efficiency of different reaction time (concentration of eluents $=0.1 \mathrm{~mol} / \mathrm{L}$, liquid $/$ solid $=10$ )

\subsection{Influence of Eluents Liquid/Solid Ratio}

Lead and arsenic extraction efficiencies for different solution/soil ratios are present in Figure 4. Extraction time for these experiments was 2 hours. Concentration of eluents was $0.1 \mathrm{~mol} / \mathrm{L}$. When the solution/soil ratio increased from 3 to 20, the removal of lead by EDTA was increased from $22.28 \%$ to $45.26 \%$, while the removal of arsenic by MA was increased from $7.71 \%$ to $20.88 \%$, and the removal of lead and arsenic by CA were increased from $13.31 \%$ to $40.01 \%$ and $4.04 \%$ to $20.88 \%$, respectively. However, on the one hand, increased dose of eluents were not fully convicted to extract the compounds but form complexes with other cations (Fe, $\mathrm{Al}$, etc.) $[8,9]$. On the other hand, soil wash would generate large amount of wastewater, which would increased the cost.

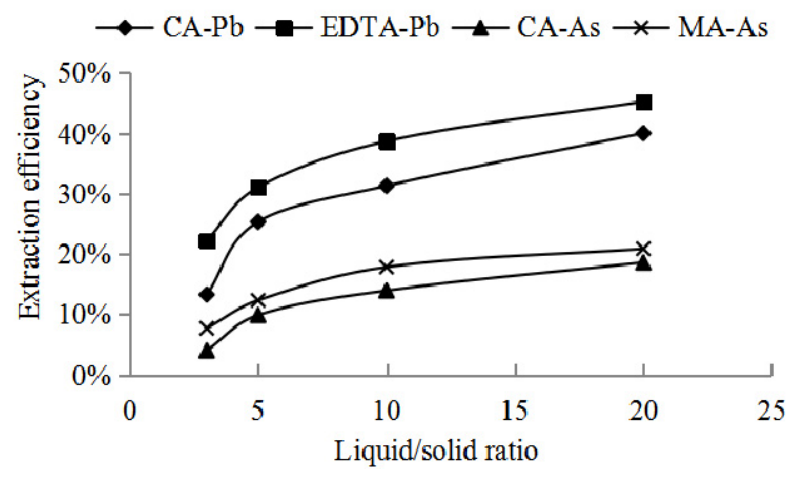

Figure 4. Extraction efficiency of lead/arsenic with different liquid/solid ratios. (concentration of eluents $=0.1 \mathrm{~mol} / \mathrm{L}$, reaction time $=2 \mathrm{~h}$ )

\section{Conclusions}

Effectiveness of CA, PA, MA and EDTA of removing lead and arsenic from contaminated soil was examined in the soil washing processing. The best eluent for lead contaminated soil was EDTA, the best eluents for arsenic contaminated soil was $\mathrm{CA}$ and $\mathrm{MA}$, and the best eluent for lead-arsenic-contaminated soil was CA. The removal efficiencies of lead and arsenic with different eluents were increased with increasing extractant. The critical level of EDTA, CA and MA in this study was 0.1 $\mathrm{mol} / \mathrm{L}$. The process of eluents extracting lead/arsenic from the contaminated soil included two step adsorptions, in which a rapid desorption within the first 2 hours was followed by a subsequent gradual release that occurred over the following hours. At the same time, the liquid/solid ratio was an important parameter to control the extracting reaction. But the higher liquid/solid ratio would generate wastewater and increase the cost of soil remediation.

\section{References}

1. Q.Q. Yang, Z.Y. Li, X.N. Lu, et al. A review of soil heavy metal pollution from industrial and agricultural regions in China: Pollution and risk assessment[J]. Science of the Total Environment, 642: 690-700 (2018)

2. Q. Duan, J.C. Lee, Y.S. Liu, et al. Distribution of Heavy Metal Pollution in Surface Soil Samples in China: A Graphical Review[J]. Bulletin of Environmental Contamination and Toxicology, 97: 303-309 (2016)

3. Z.X. Luoa, M.R. Gaob, X.S. Luo, et al. National pattern for heavy metal contamination of topsoil in remote farmland impacted by haze pollution in China[J]. Atmospheric Research, 170: 34-40 (2016)

4. L.W. Liu, W. Li, W.P. Song, et al. Remediation techniques for heavy metal-contaminated soils: Principles and applicability[J]. Science of The Total Environment, 633: 206-219 (2018)

5. G. Wang, X. Pan, S. Zhang, Q. Zhong, et al. Remediation of heavy metal contaminated soil by biodegradable chelator-induced washing: Efficiencies and mechanisms[J]. Environmental Research (2020)

doi: https:// doi.org/10.1016/j.envres.2020.109554

6. S. Cheng, Q. Lin, Y. Wang, et al. The removal of $\mathrm{Cu}, \mathrm{Ni}$, and $\mathrm{Zn}$ in industrial soil by washing with EDTA-organic acids[J]. Arabian Journal of Chemistry (2020)

doi: https://doi.org/10.1016/j.arabjc.2020.02.015

7. K.R. Reddy, S. Chinthamreddy. Comparison of Extractants for Removing Heavy Metals from Contaminated Clayey Soils. Soil and Sediment Contamination, 9, 449-462 (2000)

8. W.J. Feng, S.R. Zhang, Q.M. Zhong, et al. Soil washing remediation of heavy metal from contaminated soil with EDTMP and PAA: 
Properties, optimization, and risk assessment[J]. Journal of Hazardous Materials, 381: 120997 (2020)

9. S. Gluhar, A. Kaurin, D. Lestan. Soil washing with biodegradable chelating agents and EDTA: Technological feasibility, remediation efficiency and environmental sustainability $[\mathrm{J}]$. Chemosphere (2020)

doi.org/10.1016/j.chemosphere.2020.127226Get

rights and content 